\title{
Better Open than Intellectual: The Benefits of Investment Personality Traits for Learning
}

This manuscript has been accepted for publication in Personality and Social Psychology Bulletin in October 2017. All data files and study materials for this manuscript are available from the Open Science Framework on https://osf.io/d85wy/.

Sophie von Stumm

Department of Psychological and Behavioural Science

London School of Economics and Political Science

Queens House, Lincoln's Inn Fields, WC2 3LJ, London, UK.

Email: s.von-stumm@,1se.ac.uk

Word count: 7908 


\begin{abstract}
The investment theory of adult intelligence posits that individual differences in knowledge attainment result from people's differences in cognitive ability and their propensity to apply and invest that ability, which is referred to as investment personality traits. Here, we differentiated intellectual (i.e., intellectual curiosity) and non-intellectual investment (i.e., openness to experience), and we tested their respective predictive validity for knowledge attainment in four independent lab-based studies (overall $\mathrm{N}=649$ ). Openness to experience was positively associated with knowledge attainment across all four studies, and this effect was by and large independent of cognitive ability. By contrast, intellectual curiosity was not related to knowledge attainment. The findings suggest that openness to experience, rather than intellectual curiosity, is the investment personality trait that broadly benefits learning and adult intelligence.
\end{abstract}

Word count abstract: 136 .

Keywords: Investment personality traits; Openness; Intellectual Curiosity; Intelligence; Learning; 


\section{INTRODUCTION}

The investment theory of adult intelligence proposes that individual differences in knowledge attainment result from people's cognitive ability and their propensity to apply and invest their ability over time (Ackerman, 1996; Cattell, 1943). The interplay of ability and investment has been referred to as 'the hungry mind' that is thought to drive learning behaviors and achievement (von Stumm, Hell, \& Chamorro-Premuzic, 2011a). To date, the predictive validity of investment traits for knowledge attainment has been inferred from their positive associations with markers of adult intellect, mainly academic performance and measures of crystallized intelligence (e.g., Ackerman \& Rolfus, 1999; Fleischhauer et al., 2010; Poropat, 2009; Soubelet \& Salthouse, 2010; von Stumm \& Ackerman, 2013; Ziegler, Danay, Heene, Asendorpf, \& Bühner, 2012). However, no direct observations of the association between investment traits and the accumulation of knowledge as it occurs in realtime in typical learning situations have been reported. That is, earlier studies on the association between investment and knowledge operationalized the latter through content that was acquired outside controlled laboratory settings, for example crystallized intelligence academic performance, or information learned through personal studies (e.g., Ackerman \& Beier, 2006; Ziegler et al., 2012). Here, we tested for the first time to what extent investment traits predicted knowledge attainment across learning tasks that varied in situational constraints and cognitive demands in four independent lab-based studies. Investment Personality Traits

Investment personality traits "refer to stable individual differences in the tendency to seek out, engage in, enjoy, and continuously pursue opportunities for effortful cognitive activity" (von Stumm, Chamorro-Premuzic, \& Ackerman, 2011b, p. 225). With that, investment traits are conceptually similar to curiosity, which can "broadly defined as a desire to acquire new knowledge and new sensory experience that motivates exploratory behavior" 
(Litman \& Spielberger, 2003, p. 75). Akin to curiosity (Grossnickle, 2016), the investment trait construct space can be differentiated into two sub-domains (von Stumm et al., 2011a): the "love for knowledge" and "openness to experience" (Berlyne, 1954; Loewenstein, 1994; McCrae, 1994). Various brain imaging, behavioral genetic, and psychometric studies have substantiated that intellectual curiosity and openness to experience are related, yet distinct constructs that map the investment trait construct space (e.g., DeYoung, Grazioplene, \& Peterson, 2012; DeYoung, Samosh, Green, Braver, \& Gray, 2009; Kaufman et al., 2016; von Stumm \& Ackerman, 2013; Wainwright, Wright, Luciano, Geffen, \& Martin, 2008).

Love for knowledge, or intellectual curiosity (cf. Mussel, 2010), was initially conceptualized as a temporal motivational state that was situationally aroused and stimulated targeted information seeking (Berlyne, 1954; 1960). Under this model, intellectual curiosity was thought to emerge either when individuals were confronted with information that challenged their beliefs, attitudes or knowledge, or when they identified a gap in their existing framework of knowledge (Kang et al., 2009; Loewenstein, 1994) Both conditions were understood to prompt explorations of the environment to acquire new information that resolved the conceptual conflict or filled the knowledge gap (Berlyne, 1960).

More recently, intellectual curiosity has become recognized as a stable trait dimension of individual differences in the preference for engagement in cognitively challenging or complex tasks and intellectual leisure time pursuits (Mussel, 2013). Here, intellectual curiosity is no longer assumed to vary primarily as a function of the situation but rather because of inherent differences between people in their tendency to purposefully seek out knowledge (Goff \& Ackerman, 1992), which is at the center of the investment trait construct space (von Stumm \& Ackerman, 2013). However, limiting investment to effortful and purpose-driven knowledge seeking ignores the possible benefits of openness to experiences 
that are not readily identifiable as 'intellectual' for the accumulation of knowledge (Grossnickle, 2016).

If actively seeking out knowledge is the essence of intellectual curiosity, the readiness to cognitively engage with perception, fantasy, aesthetics, and emotions is at the core of openness (DeYoung et al., 2012; Kaufman et al., 2014). Accordingly, openness to experience has been described the "preference for the new and different in many aspects of life" (McCrae, 1994, p. 257). Although this preference not inherently aimed at knowledge attainment, openness is likely to benefit learning in everyday life, especially in situations that are not recognized as opportunities for intellectual pursuits, through engaging with perception, fantasy, aesthetics, and emotions.

\section{Divergent Predictive Validity of Openness and Intellectual Curiosity}

The differentiation of the investment trait construct space into openness and intellectual curiosity is further supported by their distinct associations with cognitive ability and academic performance (Soubelet \& Salthouse, 2010; von Stumm \& Ackerman, 2013). For one, openness is less strongly associated with cognitive ability, especially with measures of fluid intelligence, than intellectual curiosity (Fleischhauer et al., 2010; Hill et al., 2013; Mussel, 2010, 2013; Soubelet \& Salthouse; von Stumm \& Ackerman, 2013). Accordingly, cognitive ability is likely to confound associations between intellectual curiosity and knowledge to a greater extent than associations between openness and knowledge attainment. For the other, several large-scale meta-analyses reported that openness is only modestly related to academic performance with effect sizes approximating .10 (e.g., McAbee, \& Oswald, 2013; Poropat, 2009; Vedel, 2014), while meta-analytic estimates for the association between intellectual curiosity and academic performance yielded estimates of .30 (von Stumm \& Ackerman, 2013; von Stumm et al., 2011a). One study, which was based on a correlation matrix of coefficients assembled from different meta-analyses (von Stumm et al., 
2011a), even showed that intellectual curiosity was positively, but openness negatively, associated with academic performance after adjusting for the variance that both traits shared.

Overall these findings suggest that intellectual curiosity is a better predictor of academic performance than openness. However, the previous evidence suffers from two important limitations. For one, many more studies have tested associations between openness and academic performance than studies that linked intellectual curiosity and academic performance. As a consequence, meta-analyses on intellectual curiosity spanned a modest number of effect sizes and thus, are likely to produce biased estimates (cf. von Stumm \& Ackerman, 2013). For the other, no study to date has tested the divergent predictive validity of intellectual curiosity and openness for knowledge attainment as it occurs. That is, earlier studies reported associations between investment traits with various markers of previously attained knowledge, like crystallized intelligence tests and academic achievement, or knowledge that was attained outside laboratory settings (e.g., Ackerman \& Beier, 2006), but none related investment traits to knowledge in controlled study situations as learning occurred. A laboratory setting allows for comparing the predictive validity of openness and intellectual curiosity for knowledge attainment across differently restrictive learning situations, ranging from mundane experiences to formal education settings.

\section{The Current Studies}

In the current research, we sought to provide direct evidence for the divergent validity of intellectual and non-intellectual investment for knowledge attainment. To this end, we conducted four independent studies that each employed a different learning paradigm, to test investment-knowledge links across unrestricted and formal learning situations. The first was an informal everyday learning opportunity that invited participants to engage with a website at their own discretion. The second task also resembled an informal learning situation but participants were directly instructed to study brief trivia facts. In the third task, participants 
were offered rewards for learning from short articles, whose content was modestly intellectually challenging. This task resembled more closely formal learning situations than the first and second task. The final learning paradigm simulated study situations in formal education settings. Participants were prompted to study 2,000 word long, scholarly texts and promised rewards depending on their performance in a subsequent exam. After completing each task, participants answered multiple-choice questions about the tasks content to assess their learning success. We then tested to what extent intellectual curiosity and openness predicted knowledge attainment, before and after adjusting for individual differences in cognitive ability. Across studies, we predicted that intellectual curiosity was more strongly associated with knowledge attainment in learning situations that emphasized the opportunity for knowledge attainment, while openness was expected to predict learning in situations that did not demand intellectual engagement. In the following, each study is reported in detail; their respective learning tasks are described in full in the supplementary materials ( 1 to 4$)$.

\section{METHODS}

\section{Study 1}

Participants were presented with a website about the Plitvice Lakes, a picturesque lake district in Croatia, and asked to engage at their own discretion with the website, its weblinks and the therein contained information for 5 minutes. This design constituted an everyday learning situation, for which we expected positive associations for both investment traits with knowledge attainment (i.e., information recall), with larger effect sizes for openness than for intellectual curiosity. Cognitive ability was predicted to marginally attenuate the associations.

\section{Sample}


A total of 201 participants, including 108 men, 92 women and one participant who preferred not to indicate gender, were recruited from the metropolitan area of London through online advertisements (e.g., gumtree.co.uk; $\mathrm{N}=120$ ); flyers (e.g., in cafes in central London; $\mathrm{N}=41)$; university research volunteer panels $(\mathrm{N}=24)$; and approaching participants in person near the testing sites at two major London universities $(\mathrm{N}=19)$. Participants were native English speakers and had lived in the United Kingdom for 10 years or more. They ranged in age from 18 to 75 years with a mean of $33.21(\mathrm{SD}=12.71)$. The majority of the participants reported to have a university degree (63\%) and to earn less than $£ 15,000$ per annum $(51 \%)$.

Measures

Cognitive ability. Logical reasoning ability was assessed with Raven's Progressive Matrices (Set E; Raven, 1968) and the lettersets test (Ekstrom, French \& Harman, 1976). For Raven's, Twelve items showed grids of 3 rows x 3 columns each with the lower right hand entry missing. Participants chose from eight alternatives the one that completed the $3 \times 3$ matrix figure. The test was timed at 4 minutes. For lettersets, participants identified one mismatching 4-letter set, inferring a rule underlying the composition of four other 4-letter sets. The test had 12 items and was timed at 4 minutes.

Investment. Openness was assessed by the NEO-FFI scale for Openness to Experience (Costa \& McCrae, 1992) that consists of 12 items rated on a 5-point Likert scale ranging from Strongly Disagree to Strongly Agree. The scale includes 3 items from the Ideas facet of Openness to Experience, which were here excluded from the openness score (i.e., nonintellectual investment). Intellectual curiosity was assessed with the Need for Cognition scale (Caccioppo \& Petty, 1982), which consisted of 18 self-report items rated on a 5-point Likert scale ranging from Strongly Disagree to Strongly Agree. The scale has been shown elsewhere to have excellent psychometric properties (Cacioppo et al., 1996; Caccioppo \& Petty, 1982). 
Information access and recall. Information-recall was assessed by 20 multiple-choice questions on the website information about the Plitvice Lakes, each with five answer options, including one correct response (coded as 1) and "I don't know" (coded as 0 , together with incorrect responses). In addition, the time that participants spent on the Plitvice Lakes main page was recorded, as was the number of pages that participants visited over the course of 5 minutes (maximum 17).

\section{Insert Figure 1 Here}

\section{Procedure \& Apparatus}

Testing took place in designated laboratory cubicles on desktop computers at two large London universities between July and December 2013. Participants left all personal items (e.g., mobile phones) with a research assistant outside their cubicle. After completing the cognitive tests, participants were informed that they had a five-minute break, during which they were free to do whatever they preferred. They were then shown an image of the Plitvice Lakes in Croatia (Figure 1), which are part of the UNESCO World Heritage. The Plitvice Lakes were here chosen (a) because they are largely unknown in Britain, thus reducing the likelihood that participants had personal associations with or prior knowledge of the lakes, and (b) because their visual appeal was judged as likely to intrigue the people's interest. Underneath the Plitvice Lakes' image, five links were shown that could be clicked to access further information. Four included written information on Terrain, Climate, Local Customs and Flora; each of these also included three additional links leading to further information. The fifth link was a Gallery and showed six different images of the Plitvice Lakes. Overall, a maximum of 17 pages could be accessed. A pilot study $(\mathrm{N}=9)$ confirmed that all the information could be comfortably reviewed in 5 minutes. The information consisted of real and made-up facts that were simple, memorable and highly unlikely to be known outside of this study. For example, one link informed about the amount of annual 
rainfall at the Plitvice Lakes (real), and another described different orchid types of the Plitvice Lakes (fictional). On each page, a "Back" button was shown at the bottom left corner that allowed participants to navigate back to the previous pages. Afterwards, participants completed the personality measures and answered multiple-choice questions on the Plitvice Lakes, including two multiple-choice questions for each main page and one for each of the three additional links (i.e., the links within each main information page; overall 4 main links x 2 questions +3 sub-links x 4 main links x 1 question $=20$ questions). Individual testing sessions lasted approximately 30 minutes; participants received $£ 10$ compensation.

Results

Study 1 had $80 \%$ power to detect a correlation of .2 and $98 \%$ to detect a correlation of .3 (based on the analysis sample of $\mathrm{N}=184$, details below). Table 1 reports the descriptive statistics for this and the following three empirical studies; correlation matrices for each study are in the supplementary materials (0). In all studies, including the current one, scores were normally distributed and internal consistency values (i.e., reliability with Cronbach's alpha) were satisfactory. Across studies, Cronbach's alpha values were slightly higher for measures of intellectual curiosity than for openness, reflecting the difference in narrowly assessing an inclination for knowledge pursuit compared to capturing the broader openness to nonintellectual internal and external experiences.

The scores from the cognitive tests correlated at $r=.47$, were $z$-transformed and added to a unit-weighted composite of cognitive ability. For ten participants, irregularities occurred during testing (e.g., participant kept mobile phone despite instructions, or left cubicle when Plitvice Lakes main page was presented); these were excluded from all analyses $(\mathrm{N}=191)$. Seven participants $(3.7 \%)$ did not engage at all with the Plitvice Lakes page throughout the 5-minute break period, while the majority of participants spent on average 3 minutes browsing 10 out of 17 pages. Participants reported after the study that, when they 
had not viewed the Plitvice Lakes information, they had napped, dozed or stared into space. They were excluded from the subsequent analysis (i.e., analysis $\mathrm{N}=184$ ).

Openness and intellectual curiosity were positively inter-correlated $(r=.42)$. Linear regression models, adjusted for age, gender, testing location, and recruitment method, showed that openness was positively associated with the answer scores regarding website content on the Plitvice Lakes $(\beta=.24, p=.003$, CI95\% from .08 to .39) but intellectual curiosity was not $(\beta=.04, \mathrm{p}=.639, \mathrm{CI} 95 \%$ from -.12 to .20$)$, with the model accounting for $6.8 \%$ of the variance (i.e., adjusted R Square; Figure 2a). Adjusting for cognitive ability $(\beta=.13, \mathrm{p}=$ .090 , CI95\% from -.20 to .28) did not change the results, with openness remaining a significant predictor $(\beta=.22, \mathrm{p}=.006$, CI95\% from .06 to .38$)$, and the overall model accounting for $7.8 \%$ of the variance.

Insert Table $1 \&$ Figure 2 Here

\section{Discussion}

Study 1 showed that openness rather than intellectual curiosity was associated with knowledge attainment in an unconstrained everyday learning task (i.e., when studying a website). This finding confirmed only partly our hypotheses, which predicted stronger effects of openness, than of intellectual curiosity, on knowledge attainment but expected significant positive associations for both. The results suggest that intellectual curiosity does not benefit learning in situations that appear not to offer opportunities for intellectual pursuits. As predicted, cognitive ability did not confound the relationship between openness and learning. The model explained overall $7.8 \%$ of the variance in knowledge attainment, suggesting medium effect sizes for the association between openness and knowledge.

Study 2

By contrast to the learning paradigm used in Study 1, participants were directly prompted to engage with the learning materials in Study 2, when they were asked to study 
short paragraphs about trivia facts. Participants were, however, neither told that they were to be examined on the content of trivia facts nor were they incentivized to attain knowledge. Because Study 2 emphasized the opportunity for knowledge attainment to a similar degree as Study 1, we predicted that openness, but not intellectual curiosity would benefit learning, and that cognitive ability would not affect these associations, in line with the findings from Study 1.

\section{Sample}

Overall 179 participants were recruited, including 131 prospective university students and their parents who were approached during the Open Days at two major London universities and compensated with sweets and crisps, as well as 48 undergraduate students, who participated in exchange for course credits. Participants who spent less than 90 seconds completing the logical reasoning test (i.e., lettersets) were excluded from all analyses $(\mathrm{N}=9)$. The majority of the analysis sample identified as female $(\mathrm{N}=148$ of $170 ; 83 \%)$, and ages ranged from 15 to 65 years $(\mathrm{M}=23.30, \mathrm{SD}=11.34)$. The majority had had obtained a school leaving certificate as highest educational qualification (77\%).

\section{Measures}

Cognitive ability. In addition to the lettersets ${ }^{1}$ test from Study1, participants completed a short-term memory test (von Stumm, 2016). The test consisted of 10 series of 5 and 7 number pairs or pairs of numbers and letters that were presented for 5 and 10 seconds, respectively. Participants were then asked to recall in the order that the pairs were shown in within 25 and 30 seconds, respectively (total $n=58$ ).

Investment. By contrast to Study1, intellectual curiosity was operationalized by the NEO-PI-R Ideas facet (Costa \& McCrae, 1992), which can be used interchangeably with the Need for Cognition scale (DeYoung et al., 2012; Mussel, 2010; von Stumm \& Ackerman, 
2013). Openness was again measured by the NEO-FFI scale, excluding 3 items from the Ideas facet.

Information recall. Participants completed 10 multiple-choice questions that assessed their factual recall and conceptual understanding of the 5 short articles $(2$ questions per article). Each question had 5 answer options, including the correct answer and one "I don't know" option. Correct answers were coded as 1, and all others as 0 .

\section{Procedure \& Apparatus}

Testing took place in designated research cubicles on desktop computers at two major London universities between June 2014 and October 2015. Participants left all personal items (e.g., mobile phones) with a research assistant outside their cubicle. Participants read in their own time through the trivia fact articles, which ranged in length between 90 and 119 words. The trivia facts were unlikely to be known outside of this study and included (1) spotting lying in the face, (2) sign language, (3) English freedom medals, (4) Guinness World of Records most dangerous tree, and (5) placebo and nocebo effects. After the reading, participants completed cognitive and personality tests, and then answered the multiple-choice questions.

Results

The study had a power of $75 \%$ to detect an association of . 2 and a power of $98 \%$ to detect a correlation of .3 (based on the analysis sample $\mathrm{N}=170$ ). Cognitive test scores correlated at $r=.30$, which reflects the very different nature of the two administered cognitive tests. A composite of cognitive ability was computed like in Study 1. Openness and intellectual curiosity correlated at $r=.45$.

A multiple regression model, adjusted for age and gender, showed that openness predicted learning significantly $(\beta=.19, \mathrm{p}=.032$, CI95\% from .02 to .37$)$ but intellectual curiosity did not $(\beta=-.04, p=.616$, CI95\% from -.22 to .13$)$, with the model accounting for 
$2.2 \%$ of the variance in recall (i.e., adjusted R Square; Figure $2 b$ ). Adjusting for cognitive ability $(\beta=.10, p=.184$, CI95\% from -.05 to .25$)$ did not change these results, with openness remaining a significant predictor $(\beta=.19, \mathrm{p}=.038, \mathrm{CI} 95 \%$ from .01 to .36$)$ and the model accounting for $2.7 \%$ of the variance.

\section{Discussion}

Study 2 confirmed Study 1's finding that openness, not intellectual curiosity benefitted knowledge attainment in an everyday learning task. By contrast to Study 1, where participants engaged with the learning materials at their own discretion, participants in Study2 were directly prompted to study. Thus, openness' learning-related benefits for knowledge appear not to be restricted to completely unconstrained learning situations but they also emerged in a more guided learning context. Like in Study1, the association between openness and learning was independent of cognitive ability. The effect size of the association between openness and information recall was comparable to Study1, but the overall model accounted for far less variance (i.e., $7.8 \%$ versus $2.6 \%$ ).

\section{Study 3}

As in Study 2, participants were directly prompted to engage with the study materials, in this case five texts about film-related topics. By contrast to Study 1 and 2, participants were informed that they would be examined on the study materials, and they were incentivised to perform well by the chance to win $£ 20$ for a top score. Accordingly, the current learning task was more constrained than those in Study 1 and 2, although the film texts were only modestly cognitively demanding, implying little opportunity for intellectual mastery. Thus, we expected to replicate our findings from Study 1 and 2, with openness emerging as stronger predictor of knowledge attainment compared to intellectual curiosity.

\section{Sample}


A total of 130 participants attended lab-based testing sessions, including prospective students and their parents, who were approached at university Open Day events, and undergraduate students. From the overall sample, 32 participants were excluded because they either (a) failed one of three quality control items $(\mathrm{N}=24)$ or $(\mathrm{b})$ spent less than 2 minutes reading the study materials $(\mathrm{N}=8)$. Thus, the analysis sample consisted of 98 participants aged 16 to 56 years $($ mean $=22.0 ; \mathrm{SD}=8.4)$. Just over half reported school leaving certificates as highest educational qualification (56\%). Participants were compensated with sweets and crisps (Open Days) and course credits (undergraduates).

\section{Measures}

Cognitive ability. The same tests as in Study 2 were administered.

Investment. Openness and intellectual curiosity were assessed as described in Study 2.

Information recall. Participants completed 6 multiple-choice questions for each of the 5 film articles, with 3 assessing factual information recall and 3 capturing conceptual understanding (i.e., 30 questions overall). Each question had 5 answer options, including the correct answer and one "I don't know" option. To stop participants from trying to look up the answers elsewhere rather than recalling them from memory, questions were timed according to with their complexity and length, allowing between 12 and 28 seconds for an answer (mode $=20$ seconds). The materials were repeatedly piloted and revised prior to the actual testing phase $(\mathrm{N}=22)$.

\section{Procedure \& Apparatus}

Testing took place in designated laboratory spaces on desktop computers at three UK universities between July 2015 and March 2016. Participants left all personal items (e.g., mobile phones) with a research assistant outside their cubicle. They were then instructed that they could earn $£ 20$ if they correctly answered all later multiple-choice questions about the content of the film articles that they were asked to read. Participants were advised that the 
questions were timed, and that they could and should not cheat on them. Film was chosen as a topic because it attracts wide public interest. The articles were specifically created to ensure that their content was unlikely to be known outside of this study, with topics including (1) general introduction to film, (2) film industry and funding, (3) advances in film technology, (4) film actors and stars, and (5) film awards and prizes. Articles ranged in length from 266 to 356 words (mean $=311$ words), and they were each presented for a maximum of 120 seconds. After reading the articles, participants completed the cognitive tests and personality measures and reported their five favorite movies, before answering 30 multiple-choice questions on the articles' content.

\section{Results}

Study 3 had a power of $50 \%$ to detect a correlation of .2, and a power of $85 \%$ to detect a correlation of .3 (based on the analysis sample $\mathrm{N}=98$ ). The cognitive ability test scores correlated at $\mathrm{r}=.41$, and a composite was computed as in Study 1. Openness and intellectual curiosity correlated at $r=.43$. A multiple regression model, adjusted for age, gender, and being a native English speaker versus not, showed that openness was significantly associated with knowledge attainment $(\beta=.27, \mathrm{p}=.017, \mathrm{CI} 95 \%$ from .05 to $.50)$, but intellectual curiosity was not $(\beta=-.07, \mathrm{p}=.554$; CI95\% from -.30 to .16 , Figure $2 \mathrm{c})$. However, the model's adjusted R-Square suggested that it accounted only for $1.8 \%$ of the variance in recall. After adding cognitive ability, the model accounted for $9.3 \%$ of the variance, with both openness $(\beta=.27, \mathrm{p}=.014, \mathrm{CI} 95 \%$ from .06 to .49$)$ and cognitive ability $(\beta=.30, \mathrm{p}=.004, \mathrm{CI} 95 \%$ from .10 to .50$)$ emerging as significant predictors.

\section{Discussion}

As in Study 1 and 2, openness significantly predicted knowledge attainment but intellectual curiosity did not. Also confirming the findings of Study 1 and 2 , the association between openness and learning was independent of cognitive ability. That said, cognitive 
ability was a significant predictor of knowledge attainment and accounted for the largest proportion of variance, by contrast to openness, which only explained a very small amount of variance.

Study 4

For our final study, we sought to simulate a formal learning situation that (a) was more restricted than the paradigms used in Study 1 through 3, (b) offered opportunity for intellectual mastery, and (c) and demanded effortful cognitive engagement. Participants attended three lab-based study sessions over the course of three weeks. Each week, participants studied an unknown scholarly text of approximately 2,000 words length that focused on history, science and economics, respectively. Afterwards, they completed examstyle multiple-choice questions on the current as well as on the previous weeks' study topics. Participants were incentivised each week to get as many exam questions as possible right by the chance to win $£ 50$ each week for the top score, in addition to the participants' baseline compensation fee.

In line with previous meta-analyses that showed weak associations between openness and academic performance (McAbee \& Oswald, 2013; Poropat, 2009; Vedel, 2014) and stronger links between intellectual curiosity and academic performance (von Stumm \& Ackerman, 2013), we expected here that intellectual curiosity rather than openness would predict knowledge attainment. We also hypothesized that cognitive ability would attenuate the association between intellectual curiosity and learning, following on from earlier studies that reported substantial shared variance between intellectual curiosity and intelligence (e.g., Fleischhauer et al., 2010; Hill et al., 2013).

Sample

Overall, 233 participants were recruited, of whom 229 completed all measures relevant to this study ${ }^{2}$ in week 1, while 206 participants completed week 2, and 197 
participants attended week 3. After excluding participants who spent less than 60 seconds on each week's learning task the analysis sample consisted of 180 participants with complete data (44 men, 135 women, 1 who preferred not to say). Ages ranged from 18 to 58 (mean= $26.48, \mathrm{SD}=10.26)$. Almost $81 \%$ of the participants were undergraduate students; the remainders were adult volunteers, who were recruited through newspaper advertisements and flyers in local businesses.

\section{Measures}

Cognitive ability. The lettersets test as described in Study 1 was administered.

Investment. Openness and intellectual curiosity were assessed as described in Study 2.

Information recall. Each week, participants completed 8 exam-style multiple-choice questions on the current week's text. In addition, they also completed 8 exam-style multiplechoice questions on the previous weeks' texts in week 2 and 3 (i.e., 16 questions overall in week 2 and 24 questions in week 3). Half of the questions pertaining to the previous weeks' texts had also been administered in the previous week, and half were new questions. For all questions, half assessed factual and half conceptual knowledge conceptual knowledge. Each question had 5 answer options, one being correct and one being 'I don't know'.

\section{Procedure \& Apparatus}

Testing took place in designated laboratory spaces on desktop computers with speakers at a London university between March 2016 and January 2017. Participants left all personal items (e.g., mobile phones) with a research assistant outside their cubicle. In week 1, they were randomly allocated to either read or listen to each week's 2,000 words text ${ }^{3}$, which had been specifically written for this study and featured three different scholarly topics, including history (i.e., the Cuban Missile Crisis), science (i.e., CRISPR), and economics (i.e., the Dotcom bubble). Participants were instructed that they could win $£ 50$ if they achieved a top score in a set of exam-style multiple-choice questions that they were to complete after the 
study period. In the listening condition, participants heard via headphones the 20 minute long digital records of the texts that were read out by a professional speaker (i.e., a male priest). In the reading condition, participants viewed the text on screen. Participants received pens and notepaper to take notes on the text or recording, if they wanted, and they were allowed to reread or re-listen to the texts as long as they wished. Precautions were taken to avoid that participants copied the texts. After the participants finished studying the current week's text, they called for a research assistant, who removed the notepaper. In week 1, participants then completed measures of cognitive ability and personality ${ }^{1}$, before they answered the examstyle multiple-choice questions. In weeks 2 and 3, participants completed other self-report measures ${ }^{1}$, before answering the multiple-choice questions. After completing week 3 , each participant received $£ 40$ compensation, as well as prize money of up to $£ 150$ for the highest scorers.

Results

This study had a power of $78 \%$ to detect a correlation of .2 and a power of $98 \%$ to detect an association at .3 (based on the analysis sample of $\mathrm{N}=180$ ). Openness and intellectual curiosity correlated at .42 . Knowledge attainment was operationalized as immediate recall (i.e., responses to multiple-choice exam questions pertaining to the current week's text, $\mathrm{n}_{\text {questions }}=24$ ) and delayed recall (i.e., responses to multiple-choice exam questions pertaining to the previous weeks' text, $\mathrm{n}_{\text {questions }}=16$; Table 1).

Linear regression models showed that openness was significantly associated with immediate recall $(\beta=.24, \mathrm{p}=.003$, CI95\% from .08 to .39 , Figure $2 \mathrm{~d})$, after adjusting age, gender, being a native English speaker versus not, having dyslexia versus not and learning condition (i.e., audio versus reading). Intellectual curiosity was, however, not significantly associated with immediate recall $(\beta=.11, \mathrm{p}=.159$, CI95\% from -.04 to .27$)$, with the model accounting overall for $8.8 \%$ of the variance in recall. Cognitive ability significantly predicted 
immediate recall $(\beta=.25, \mathrm{p}<.001, \mathrm{CI} 95 \%$ from .11 to .39$)$ and attenuated its association with openness $(\beta=.19, \mathrm{p}=.015, \mathrm{CI} 95 \%$ from .04 to .34$)$, with the model accounting overall for $14.6 \%$ of the variance.

For delayed recall, openness was also a significant predictor $(\beta=.19, \mathrm{p}=.020$, CI95\% .03 to .34) and intellectual curiosity was not $(\beta=.12, p=.130 ;$ CI95\% from -.04 to .28 , Figure $2 \mathrm{e}$ ), with the model accounting for $7.8 \%$ of the variance. After adding cognitive ability $(\beta=.18, \mathrm{p}=.014, \mathrm{CI} 95 \%$ from .04 to .32$)$, the association between openness and delayed recall became non-significant $(\beta=.15, \mathrm{p}=.056$, CI95\% from $<-.01$ to .31$)$, with the model accounting for $10.5 \%$ of the variance.

\section{Discussion}

Contradicting our hypothesis, intellectual curiosity was not associated with knowledge attainment in this comparatively constrained and cognitively demanding learning task. Instead, openness was again the better predictor of learning success, including both immediate and delayed recall, with corresponding models accounting for around $8 \%$ of the variance. That said, cognitive ability also significantly predicted immediate and delayed knowledge attainment, and notably attenuated their association with openness. It therefore appeared in Study 3 and 4 that cognitive ability, rather than intellectual curiosity gained predictive strength in the learning task that was highest in situational constraints and cognitive demands.

\section{GENERAL DISCUSSION}

The hungry mind concept posits that the interplay between cognitive ability and investment personality traits is at the core of the learning process and thus, informs knowledge attainment. Here, we differentiated two domains within the investment trait construct space, namely openness and intellectual curiosity (DeYoung et al., 2009; 2012; Grossnickle, 2016; von Stumm \& Ackerman, 2013; Wainwright et al., 2008), and we tested 
their predictive validity for knowledge attainment across four controlled learning tasks. Openness refers to the tendency to cognitively engage with perception, fantasy, aesthetics, and emotions (DeYoung et al., 2012; Kaufman et al., 2016). By contrast, intellectual curiosity captures individual differences in the preference for engaging in mentally challenging tasks and the purposeful pursuit of knowledge (Goff \& Ackerman, 1992; Mussel, 2013).

\section{Openness, not Intellectual Curiosity predicts Learning}

Across the four studies reported here, intellectual curiosity and openness were intercorrelated with r-values ranging from .42 to .45 , suggesting up too $20 \%$ common variance. Notwithstanding their empirical overlap, we found here reliable evidence for conceptually and operationally differentiating openness from intellectual curiosity. Specifically, we showed for the first time that openness, but not intellectual curiosity, benefitted knowledge attainment across learning tasks that varied in situational constraints and cognitive demands. This finding is surprising, given that previous studies reported substantial positive associations between intellectual curiosity and markers of adult intellect, such as academic performance and measures of crystallized intelligence (Ackerman \& Rolfus, 1999; Fleischhauer et al., 2010; Soubelet \& Salthouse, 2010; von Stumm \& Ackerman, 2013; von Stumm et al, 2011a). Although we might have expected that a preference for intellectual leisure time pursuits and cognitive mastery was unrelated to learning in mundane situations (e.g., website reading, trivia facts; Study 1 and 2), intellectual curiosity was expected to prompt knowledge attainment in more constrained and challenging learning contexts, which were simulated in Study 3 and 4 akin to learning situations at school and university.

Conversely, a substantial body of empirical evidence has suggested that openness was a weak predictor of learning achievement in formal education (e.g., McAbee, \& Oswald, 2013; Poropat, 2009; von Stumm et al, 2011a; Vedel, 2014), but it emerged here as a stable and strong predictor of knowledge attainment across tasks. 
We can only speculate about the reasons for the discrepancy between the current and previous findings. For one, it is possible that earlier meta-analyses overestimated associations between intellectual curiosity and knowledge attainment, because they relied on few, heterogeneous studies (von Stumm \& Ackerman, 2013; von Stumm et al., 2011a). For the other, meta-analytic associations between openness and knowledge attainment may have been systematically underestimated, because openness is not yet routinely differentiated in research into open and intellectual investment (DeYoung et al., 2012; DeYoung et al., 2009; von Stumm et al., 2011a).

A necessary next step in explaining the findings will be identifying the behavioral mechanisms that explain the association between investment personality traits and knowledge attainment. Two previous studies tested if engaging in cognitively stimulating activities -- for example attending evening classes or visiting museums and theatres -- mediated the relationship between investment and knowledge but found no supporting evidence (Soubelet \& Salthouse, 2010; von Stumm, 2012). An alternative behavioral mechanism to explain the investment-learning link is the ways in which people construe their learning experiences (Stine-Morrow, 2007). However, the notion of individual differences in construing experiences is difficult to study in terms of directly observable behaviors. That said, it seems plausible that the persistent benefits of openness for learning emerged here because openness predisposes to perceiving and extracting information across situations, including mundane day-to-day experiences, as well as more cognitively challenging undertakings.

\section{Investment, Cognitive Ability, and Knowledge}

Across four learning paradigms, the relationship between openness and knowledge attainment was by and large independent of cognitive ability, which was assessed by short tests in the current research, rather than through a comprehensive battery of measures. Thus, it remains possible that the observed associations are confounded by cognitive ability. That 
said, the predictive validity of cognitive ability for knowledge attainment was notably greater in Study 3 and 4, which were more constrained and cognitively demanding, than in Study 1 and 2. Furthermore, cognitive ability attenuated the association between openness and knowledge attainment in Study 4, which had the highest degree of situational constraint. The 'strong situation hypothesis' suggests that in situations of greater press -- that is, in high-stake settings where learning is hard and directly associated with reward and appraisal -- the effect of personality on behavior is weakened, while capacity-related characteristics gain predictive validity (Ackerman, 2013; Cooper \& Withey, 2009). In line with this idea, the current research showed that maximum performance measures, like cognitive ability (i.e., what a person can do), played a greater role in the strong situation learning tasks compared to those with fewer situational constraints. However, the association between openness, a typical performance measure (i.e., what a person will do), and knowledge attainment remained stable across learning tasks regardless of situational constraints, although corresponding effect sizes varied. Thus, our findings provide only partial support for the 'strong situation hypothesis'. The predictive validity of cognitive ability grew with increasing situational strength, but the effect of openness was not weakened at the same time.

\section{Strengths \& Limitations}

The research reported here has several strengths, including that each study was sufficiently powered, tested adult participants in designated lab spaces, and used reliable measures. The work is also not without weaknesses. First, the assessment of knowledge attainment relied predominantly on information recall while other aspects of learning were not assessed, for example understanding complex relationships, transferring knowledge and skills across situations, and synthesizing information. That said for all administered learning tasks, the recall questions were designed to assess both factual and conceptual knowledge of the study materials. Second, the current research only tested short-term associations between 
investment traits and knowledge attainment, either within one assessment session or across one week. Going forward, longitudinal studies must substantiate the hungry mind concept and test the long-term effects of openness on learning (Ackerman, \& Rolfhus, 1999; Ziegler et al., 2012). Third, this research did not explore the behavioral mechanisms that give rise to the association between investment and learning. Thus, we can only speculate about the causal processes that underlie the hungry mind concept. Finally, the investment traits studied here accounted, with adjustment for covariates, for $1.8 \%$ to $8.8 \%$ of the variance in knowledge attainment, suggesting that corresponding associations range in effect sizes from small to medium. Thus, the influence of investment traits in learning may be similar, if not weaker to that of other factors, which were not presently assessed, for example interest or conscientiousness.

\section{Conclusions}

The current research empirically supported the hungry mind concept that views investment personality traits and cognitive ability as key determinants of knowledge attainment. Specifically, we showed that open investment benefitted learning across four tasks that varied in situational constraints and cognitive demands. By contrast, intellectual curiosity was not associated with knowledge attainment for any learning task. Our findings propose assessing and treating openness and intellectual curiosity as separate entities in future research to identify replicable associations between investment and learning. More importantly, our results also suggest that it is better to be open, rather than intellectual for accumulating knowledge. 


\section{DECLARATION OF CONFLICTING INTERESTS}

The author declared no potential conflicts of interest with respect to the research, authorship, and publication of this article.

\section{FUNDING}

This research was supported by the Eysenck Memorial Award 2012 and by Grant RFP-15-03 from the Imagination Institute (www.imagination-institute.org), funded by the John Templeton Foundation. SvS is supported by a Jacobs Research Foundation Fellowship 2017-2019. Barnaby Brien, Yordanka Dimova, Ian Hannent, Alan Mak, Hannah Scott, and Abegail Tan helped with the data collection, stimuli design, and technical support. 


\section{REFERENCES}

Ackerman, P. L. (1996). A theory of adult intellectual development: Process, personality, interests, and knowledge. Intelligence, 22, 227-257.

Ackerman, P. L. (2013). Personality and cognition. In S. Kreitler (Ed.), Cognition and motivation: Forging an interdisciplinary perspective (pp. 62-75). Cambridge: Cambridge University Press.

Ackerman, P. L., \& Beier, M. E. (2006). Determinants of domain knowledge and independent study learning in an adult sample. Journal of Educational Psychology, 98, 366381.

Ackerman, P. L., Chamorro-Premuzic, T., Furnham, A. (2011). Trait complexes and academic achievement: Old and new ways of examining personality in educational contexts. British Journal of Educational Psychology, 81, 27-40.

Ackerman, P. L., \& Rolfhus, E. L. (1999). The locus of adult intelligence: Knowledge, abilities, and non-ability traits. Psychology and Aging, 14, 314-330.

Berlyne, D. E. (1954). A theory of human curiosity. British Journal of Psychology, 45, 180191.

Berlyne, D. E. (1960). Conflict, arousal, and curiosity. New York: McGraw-Hill.

Cacioppo J. T., \& Petty, R. E. (1982). The need for cognition. Journal of Personality and Social Psychology, 42, 116-131.

Cacioppo, J. T., Petty, R. E., Feinstein, J., \& Jarvis, W. B. G. (1996). Dispositional differences in cognitive motivation: The life and times of individuals varying in need for cognition. Psychological Bulletin, 119, 197-253.

Cattell, R. B. (1943). The measurement of adult intelligence. Psychological Bulletin, 40, 153193. 
Cooper, W. H., \& Withey, M. J. (2009). The strong situation hypothesis. Personality and Social Psychology Review, 13, 62-72.

Costa, P. T., \& McCrae, R. R. (1992). Revised NEO Personality Inventory (NEO-PI-R) and NEO Five-Factor Inventory (NEO-FFI): Professional manual. Odessa, FL:

Psychological Assessment Resources.

Fleischhauer, M., Enge, S., Brocke, B., Strobel, A. \& Strobel, A. (2010). Same or different? Clarifying the relationship of Need for Cognition to personality and intelligence. Personality and Social Psychology Bulletin, 36, 82-96.

DeYoung, C. G., Grazioplene, R. G., \& Peterson, J. B. (2012). From madness to genius: The Openness/Intellect trait domain as a paradoxical simplex. Journal of Research in Personality, 46, 63-78.

DeYoung, C. G., Shamosh, N. A., Green, A. E., Braver, T. S., \& Gray, J. R. (2009). Intellect as distinct from Openness: Differences revealed by fMRI of working memory. Journal of Personality and Social Psychology, 97, 883-892.

Ekstrom, R. B., French, J. W., \& Harman, H. H. (1976). Manual for kit of factor-referenced cognitive tests. Princeton, NJ: Educational Testing Service.

Goff, M., \& Ackerman, P. L. (1992). Personality-intelligence relations: Assessment of typical intellectual engagement. Journal of Educational Psychology, 84, 537-552.

Grossnickle, E.M. (2016). Disentangling curiosity: Dimensionality, definitions, and distinctions from interest in educational contexts. Educational Psychology Review, 28(1), 23-60.

Hill, B. D., Foster, J., Elliott, E. M., Shelton, J. T., McCain, J., \& Gouvier, W. D. (2013).

Need for cognition is related to higher general intelligence, fluid intelligence, and crystallized intelligence, but not working memory. Journal of Research in Personality, 47, 22-25. 
Kaufman, S. B., Quilty, L. C., Grazioplene, R. G., Hirsh, J. B., Gray, J. R., Peterson, J. B., \& DeYoung, C. G. (2014). Openness to Experience and Intellect differentially predict creative achievement in the arts and sciences. Journal of Personality, 84(2), 248-258.

Litman, J. A., \& Spielberger, C. D. (2003). The measurement of epistemic curiosity and its diversive and specific components. Journal of Personality Assessment, 80, 75-86.

Loewenstein, G. (1994). The psychology of curiosity: A review and reinterpretation. Psychological Bulletin, 116, 75-98.

McAbee, S. T., \& Oswald, F. (2013). The criterion-related validity of personality measures for predicting GPA: A meta-analytic validity competition. Psychological Assessment, 25, 532- 544.

McCrae, R. R. (1994). Openness to experience: Expanding the boundaries of Factor V. European Journal of Personality, 8, 251-272.

Mussel, P. (2010). Epistemic curiosity and related constructs: Lacking evidence of discriminant validity. Personality and Individual Differences, 49, 506-510.

Mussel, P. (2013). Intellect: a theoretical framework for personality traits related to intellectual achievements. Journal of Personality and Social Psychology, 104, $885-906$.

Poropat, A. E. (2009). A meta-analysis of the Five Factor model of personality and academic performance. Psychology Bulletin, 135, 322 - 338.

Raven, J. C. (1968). Progressive matrices: A perceptual test of intelligence. London: H. K. Soubelet, A., \& Salthouse, T. A. (2010). The role of activity engagement in the relations between Openness/Intellect and cognition. Personality and Individual Differences, 49, 896-901. 
Stine-Morrow, E. A. L. (2007). The Dumbledore Hypothesis of cognitive aging. Current Directions in Psychological Science, 16, 300-304.

von Stumm, S. (2012). Investment Trait, Activity Engagement, and Age: Independent Effects on Cognitive Ability. Journal of Aging Research, doi:10.1155/2012/949837.

von Stumm, S. (2016). Is day-to-day variability in cognitive function coupled with day-today variability in affect? Intelligence, 55,1-6.

von Stumm, S., \& Ackerman, P. L. (2013). Investment and Intellect: A Review and Metaanalysis. Psychological Bulletin, 139, 841-869.

von Stumm, S., Chamorro-Premuzic, T., Ackerman, P. L. (2011b). Re-visiting intelligencepersonality associations: Vindicating intellectual investment. In T. ChamorroPremuzic, S. von Stumm, \& A. Furnham (eds.), Handbook of Individual Differences. Chichester, UK: Wiley-Blackwell.

von Stumm, S., Hell, B., \& Chamorro-Premuzic, T. (2011a). The hungry mind: Intellectual curiosity as third pillar of academic performance. Perspectives on Psychological Science, 51, 12-31.

Vedel, A. (2014). Big Five personality group differences across academic majors : A systematic review. Personality and Individual Differences, 192, 1-10.

Wainwright, M. A., Wright, M. J., Luciano, M., Geffen, G. M., Martin, N. G. (2008). Genetic covariation among facets of openness to experience and general cognitive ability. Twin Research and Human Genetics, 11, 275-286.

Ziegler, M., Danay, E., Heene, M., Asendorpf, J., \& Bühner, M. (2012). Openness, fluid intelligence, and crystallized intelligence: Toward an integrative model. Journal of Research in Personality, 46, 173-183. 


\section{FOOTNOTES}

${ }^{1}$ Due to a technical error, participants completed only 11 of the 12 items of the lettersets test.

${ }^{2}$ Participants also completed several measures and tasks that are not relevant to the current analyses. These are not reported here.

${ }^{3}$ The study conditions were not relevant to the current analyses and are therefore not further discussed in detail. 


\section{TABLES}

Table 1

Descriptives for investment traits, cognitive ability, and recall across studies 1 through 4

\begin{tabular}{|c|c|c|c|c|c|c|c|}
\hline & Min & Max & Mean & SD & $\alpha$ & Skew & Kurtosis \\
\hline \multicolumn{8}{|l|}{ Study $1(\mathrm{~N}=191)$} \\
\hline Openness & 2.11 & 4.89 & 3.62 & 0.49 & .62 & -0.08 & 0.05 \\
\hline Intellectual curiosity & 2.22 & 4.94 & 3.54 & 0.52 & .88 & 0.10 & -0.26 \\
\hline Lettersets & 0 & 12 & 7.25 & 2.57 & .78 & -0.39 & -0.14 \\
\hline Raven's matrices & 0 & 12 & 5.59 & 2.86 & .82 & -0.35 & -0.70 \\
\hline Plitvice recall* & 0 & 19 & 8.03 & 4.43 & - & 0.11 & -0.76 \\
\hline \multicolumn{8}{|l|}{ Study $2(N=170)$} \\
\hline Openness & 2.00 & 4.78 & 3.43 & 0.56 & .64 & 0.05 & -0.69 \\
\hline Intellectual curiosity & 1.75 & 5.00 & 3.64 & 0.60 & .74 & -0.16 & -0.04 \\
\hline Lettersets & 0 & 11 & 5.46 & 2.22 & .71 & 0.25 & -0.13 \\
\hline Short-term memory & 11 & 42 & 21.74 & 5.92 & .75 & 0.68 & 0.50 \\
\hline Trivia recall & 0 & 7 & 2.92 & 1.50 & - & 0.26 & -0.18 \\
\hline \multicolumn{8}{|l|}{ Study $3(N=98)$} \\
\hline Openness & 1.88 & 4.88 & 3.50 & 0.55 & .65 & -0.07 & 0 \\
\hline Intellectual curiosity & 2 & 5 & 3.71 & 0.61 & .77 & -0.10 & -0.26 \\
\hline Lettersets & 2 & 12 & 6.90 & 2.22 & .69 & 0.27 & -0.52 \\
\hline Short-term memory & 11 & 43 & 23.80 & 6.46 & .78 & 0.63 & 0.52 \\
\hline Film recall & 1 & 28 & 18.54 & 5.06 & - & -1.15 & 1.87 \\
\hline \multicolumn{8}{|l|}{ Study $4(N=180)$} \\
\hline Openness & 2.22 & 4.44 & 3.58 & 0.51 & .60 & -0.57 & -0.24 \\
\hline Intellectual curiosity & 1.75 & 4.75 & 3.47 & 0.60 & .69 & -0.36 & -0.36 \\
\hline Lettersets & 1 & 12 & 6.72 & 2.25 & .66 & 0 & -0.28 \\
\hline Immediate recall & 3 & 23 & 15.40 & 4.51 & - & -0.49 & -0.48 \\
\hline Delayed recall & 0 & 15 & 8.56 & 2.95 & - & -0.15 & -0.39 \\
\hline
\end{tabular}

*Sample includes only participants who left main Plitvice Lakes page at least once $(\mathrm{N}=184)$. $\alpha$ refers to internal consistency. 


\section{FIGURES \& LEGENDS}

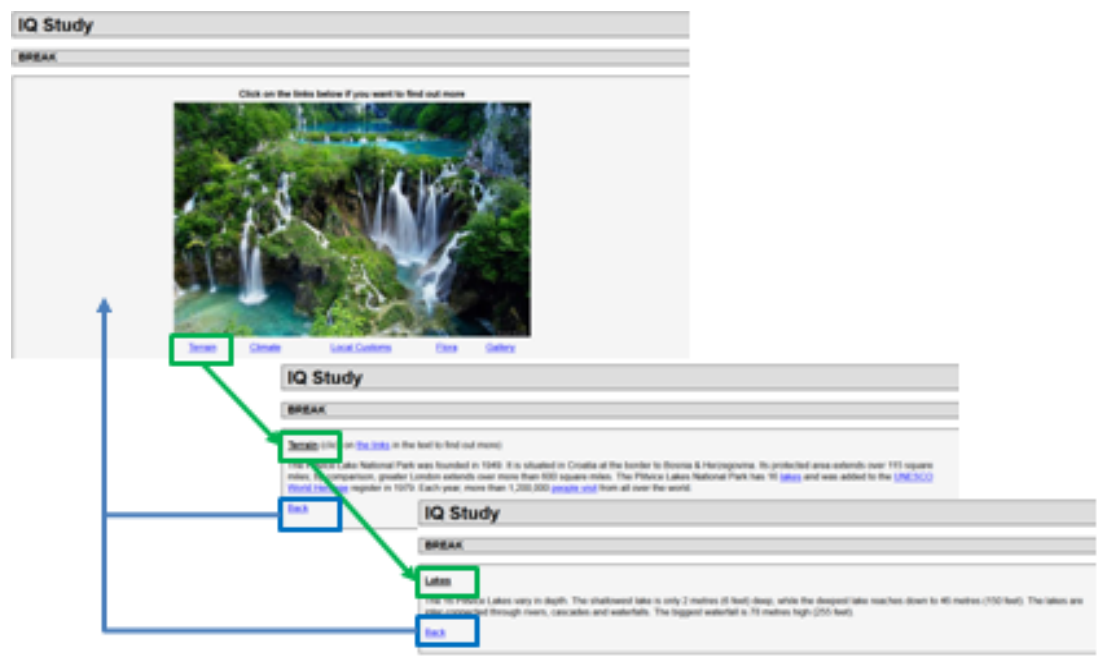

Figure 1: Plitvice Lakes stimulus: Experimental apparatus in study 1

Note. The Plitvice Lakes stimulus' main page showed an image of waterfalls (top) and five links underneath that led to more information pages. Above, the link "Terrain" is illustrated (green), which opened from the main page, led to terrain information that included three further links (i.e., Lakes, bottom). On each page, a "Back" button allowed participants to return to the previous page (blue). 

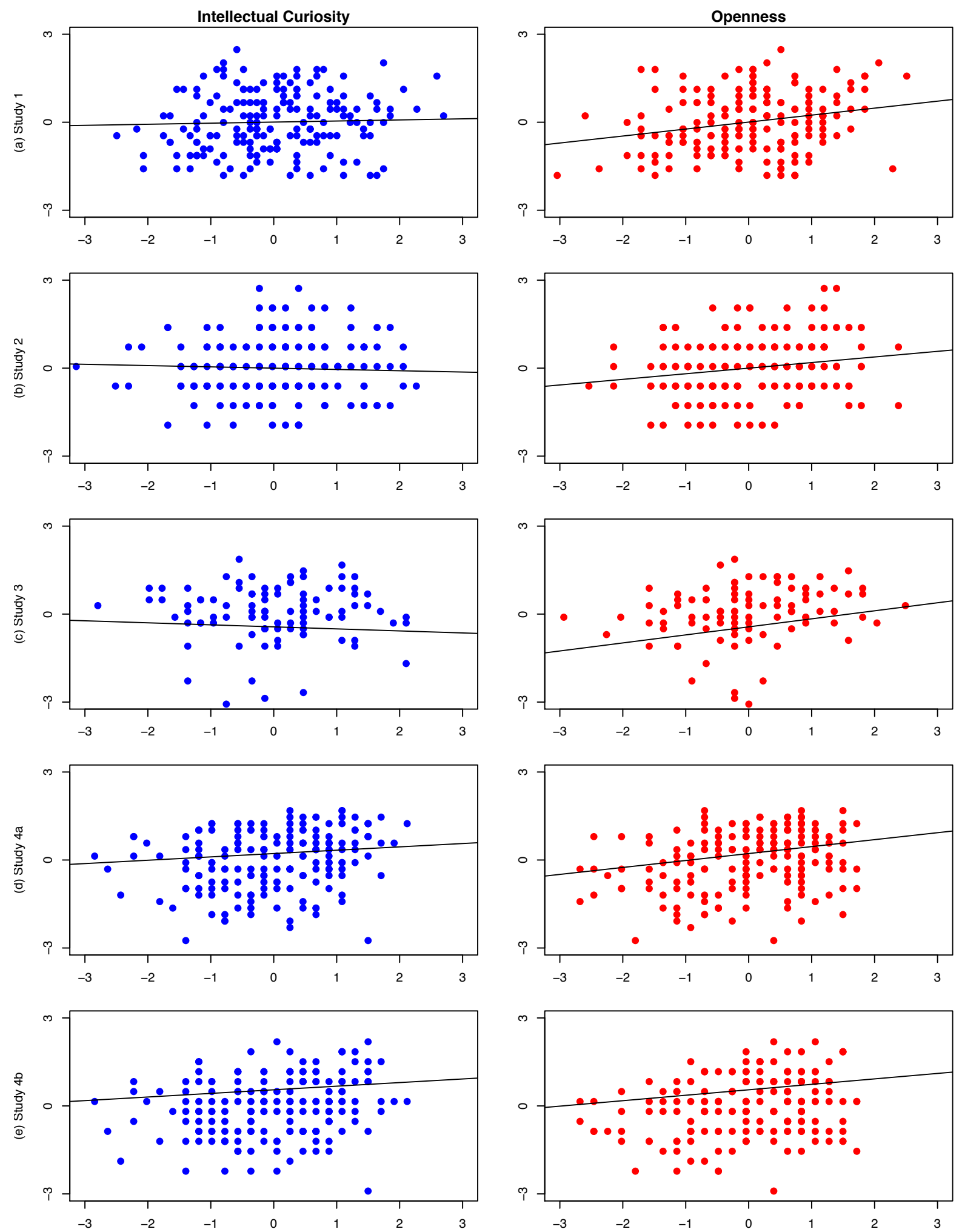

Figure 2: Regression plots for intellectual curiosity and openness on knowledge attainment across studies 1 through 4 
Note. Regression plots were adjusted for confounders (Study 1: age, gender, recruitment method, testing location; Study 2: age, gender; Study 3: age, gender, native English speaker; Study 4: age, gender, native English speaker, dyslexia, study condition), and openness and intellectual curiosity were entered simultaneously. Study $4 \mathrm{a}$ and $4 \mathrm{~b}$ refer to immediate and delayed recall, respectively. 